\title{
Detection of terpenoids and steroids in Lindsaea obtusa with thin layer chromatography
}

\author{
YUSFIA URWATUL WUTSQA ${ }^{1}$, SURATMAN ${ }^{2, \boldsymbol{v}}$, SITI LUSI ARUM SARI ${ }^{2}$ \\ ${ }^{1}$ Department of Pharmacy, STIKes KHAS Kempek. Jl. Tunggal Pegagan, Kempek, Gempol, Cirebon 45161, West Java, Indonesia \\ ${ }^{2}$ Department of Biology, Faculty of Mathematics and Natural Sciences, Universitas Sebelas Maret. Jl. Ir. Sutami 36A Surakarta 57126, Central Java, \\ Indonesia. Tel./fax. +62-271-663375, `email: suratman@staff.uns.ac.id
}

Manuscript received: 4 August 2021. Revision accepted: 21 September 2021.

\begin{abstract}
Wutsqa YU, Suratman, Sari SA. 2021. Detection of terpenoids and steroids in Lindsaea obtusa with thin layer chromatography. Biofarmasi J Nat Prod Biochem 19: 66-69. The diversity of ferns on this earth is very high, and the potential and benefits for human life are ornamental plants, food materials, and medicines. The benefits of not all ferns are known because of the lack of information on these ferns; one of the ferns is Lindsaea obtusa J. Sm. Ex Hook. The phytochemical test is the first step in research, searching for new active compounds derived from natural ingredients. This study was conducted to determine the differences in terpenoid and steroid compounds profile in $L$. obtusa extract using Thin Layer Chromatography (TLC). Extraction of $L$. obtusa using maceration techniques with methanol and n-hexane solvents. The extraction results will be used for phytochemical screening using the TLC technique with GF254 silica gel plate as a stationary phase, and a mobile phase is a chloroform: n-hexane $(9: 1 \mathrm{v} / \mathrm{v})$, n-hexane: ethyl acetate $(4: 1 \mathrm{v} / \mathrm{v})$, and methanol: ethyl acetate (5: $1 \mathrm{v} / \mathrm{v})$. Detection of terpenoid and steroids using Lieberman Burchard reagent. The result shows that $L$. obtusa extract contains terpenoid and steroid compounds. Quantitatively, the secondary metabolites of $L$. obtusa extract were soluble in methanol solvent more than the soluble compounds in $\mathrm{n}$-hexane solvent. However, qualitatively, steroid compounds that dissolve in $\mathrm{n}-$ hexane solvents have a more varied Rf value than terpenoids, especially in the mobile phase of chloroform: $\mathrm{n}$-hexane $(9: 1 \mathrm{v} / \mathrm{v})$ and $\mathrm{n}$ hexane: ethyl acetate $(4: 1 \mathrm{v} / \mathrm{v})$. L. obtusa contains more various steroid compounds than terpenoid compounds.
\end{abstract}

Keywords: Lindsaea obtusa, phytochemistry screening, thin layer chromatography, terpenoids, steroids

\section{INTRODUCTION}

The diversity of ferns on this earth is very high. There are around 13,000 species of ferns on this earth, while the ferns in Indonesia, including the Malesiana area, are estimated to be 1250-1500 species (Machfira et al. 2016). Thus, the distribution of ferns is extensive, and the potential and benefits are high enough for human life, namely ornamental plants, foodstuffs, and medicines. However, the benefits of not all ferns are known because of the lack of information about their potential, one of which is the ferns Lindsaea obtusa J. Sm. Ex Hook.

Lindsaea obtusa is a terrestrial fern $20-30 \mathrm{~cm}$ tall. These ferns have root fibers with a diameter of 1-2.5 mm and are brown. L. obtusa stem is hard, stiff, and black with a length of 4-25 cm. The leaves of $L$. obtusa are folium compositum pinnatus leaves and have black around the petiolus. Leaflets are round or oval, asymmetrical at the tip and base, smooth and green in color. L. obtusa has a round, brownish-green sorus on the leaf's underside. On one leaf, there is approximately 10-13 sorus. L. obtusa grows in forest shrubs, especially in humid areas. This fern lives 1000 meters above sea level (Dong et al. 2016). The true ferns L. obtusa live in temperate Asian regions such as Taiwan and tropical climates such as Indonesia, Java, and Bali.

The phytochemical test is an essential first step in research searching for new active compounds derived from natural ingredients. This information can be used as initial information to synthesize new drugs or to become prototypes of certain active compounds (Kruk et al., 2021). Terpenoids are also called isoprenoids because the carbon skeleton is the same as the isoprene compound. Synthesis and accumulation of terpenoid compounds contribute to medicinal properties for treating respiratory inflammation, atopic dermatitis, arthritis, and neuroinflammation, among various inflammatory diseases (Kim et al. 2020).

Steroids are lipids that do not have fatty acid groups and are not ester derivatives. Steroids are complex, fatsoluble organic molecules. This compound is a significant component of cell tissue (Rashidinejad et al., 2021). Synthetic steroids are glucocorticosteroids, estrogen, methylprednisolone, corticosteroids, androgens, squalamine, and hydrocortisone. These steroid compounds commonly treat diseases due to neurodegenerative disorders (Bansal and Singh 2018). Ferns from the Equisetaceae, Osmundaceae, Lygodiaceae, Dennstaedtiaceae, Woodsidaceae, Thelypteridaceae and Dryopteridaceae families also contain steroid compounds (Yokota et al. 2017).

The method that can be used for phytochemical screening is chromatography. Chromatography is the separation of a mixture of compounds in a sample based on differences in the interaction of the sample with the stationary and mobile phases. One of the chromatography methods used for phytochemical screening is Thin Layer Chromatography (TLC). Separation in Thin Layer Chromatography is based on differences in polarity 
between the sample and the solvent. The stationary phase is a solid applied flat in glass or aluminum as support. The mobile phase is a mixture of several liquids of different polarities. Research on the content of terpenoids and steroids in L. obtusa was minimal. Therefore, this study was conducted to determine the difference between terpenoids and steroid profiles in L. obtusa J. Sm. Ex Hook.

\section{MATERIALS AND METHODS}

\section{Sample preparation}

A sampling of L. obtusa was carried out using the cruise method, namely exploring the KGPAA Mangkunagoro I Botanical Forest Park, Ngargoyoso, Karanganyar, Central Java, Indonesia, which generally contained these ferns. The extraction process and phytochemistry screening was conducted in the Biology Laboratory, Faculty of Mathematics and Natural Sciences, Universitas Sebelas Maret, Surakarta, Indonesia.

The samples of L. obtusa ferns were separated from dirt or foreign materials and then cleaned with running water until clean. Next, this sample dried until the fern had reduced its moisture content. After drying, the sample is mashed using a blender until it becomes a powder, weighed, and used for the extraction process (Seremet et al. 2020).

\section{Secondary metabolites extraction}

The extraction of secondary metabolites was carried out by the maceration method using methanol and n-hexane as solvents. $100 \mathrm{~g}$ of $L$. obtusa powder was macerated using methanol as a solvent with a ratio of $1: 5$, which was carried out overnight. The same is done with the n-hexane solvent. The extraction process is carried out by soaking in a solvent and then filtering using filter paper. The solvent is evaporated with a rotary evaporator at $400 \mathrm{C}$, a speed of 40 rpm, and a pressure of 0.06-0.08 MPa until a thick extract is obtained for approximately 1 hour (Sati et al. 2019). The viscous extract is weighed, and the yield is calculated against the weight of the initial simplicity. The formula for the percentage of extract yield according to Wahyuni and Widjanarko (2015) is :

Yield Extract $=\frac{\text { extract weight obtained }(\mathrm{g})}{\text { extracted weight }(\mathrm{g})} \times 100 \%$

\section{Thin-layer chromatography (TLC) profile analysis}

Chemical compound profile analysis was performed on each extract using the Thin Layer Chromatography (TLC) method. First, the n-hexane and methanol extracts were eluted using the same stationary and mobile phases. This was done to determine the results indicated by different color spots on TLC for each extract (Rubiyanto 2013). Then, the n-hexane and methanol extracts were spotted on the TLC plate with the silica gel GF254 as a stationary phase and eluted using the mobile phase in the form of chloroform: n-hexane ( $9: 1 \mathrm{v} / \mathrm{v})$, n-hexane: ethyl acetate $(4: 1 \mathrm{v} / \mathrm{v})$, and methanol: ethyl acetate $(5: 1 \mathrm{v} / \mathrm{v})$ in the developer's vessel. GF254 silica gel plate was made with a width of $2 \mathrm{~cm}$ and a length of $9 \mathrm{~cm}$ and given an initial limit of $1 \mathrm{~cm}$ and an end limit of $0.5 \mathrm{~cm}$. The limit of the solvent is below the line where the spots are. The plates are removed and dried after the eluent reaches the finish line of elution.

\section{Analysis of secondary metabolite compounds}

Lieberman Burchard spray reagent has been used to detect terpenoid and steroid content from n-hexane extract and methanol extract. The terpenoid and steroid compounds observed the parameters from L. obtusa and the Rf (Retardation Factor) value (Yin et al. 2017). In thinlayer chromatography, the degree of retention is expressed as Rf, which can be formulated:

$$
\text { Retardation Factor (Rf) }=\mid \frac{\text { Distance of movement of the solute }}{\text { Distance of movement of the solvent }}
$$

Lieberman Burchard is a spotting reagent for detecting steroids and terpenoids. The Lieberman Burchard spray reagent was prepared by mixing $5 \mathrm{ml}$ of acetic acid anhydride with $5 \mathrm{ml}$ of concentrated sulfuric acid, then adding this mixture to $50 \mathrm{ml}$ of absolute ethanol. Each substance mixing was carried out by cooling. The application of this method to the TLC plate was sprayed with Lieberman Burchard reagent and then heated for 10 minutes at a temperature of $1000 \mathrm{C}$. The presence of terpenoids is indicated by the appearance of a red-violet color, while the presence of steroids is indicated by the formation of a reddish-brown color (Gummadi et al., 2021).

\section{RESULTS AND DISCUSSION}

\section{Secondary metabolite extraction}

Extraction of secondary metabolites from L. obtusa was carried out by maceration method using methanol and nhexane as solvents. The results showed that the extraction with methanol as a solvent produced a higher yield than nhexane (Table 1).

Extraction with methanol solvent resulted in $5.8 \mathrm{~g}$, so the yield percentage was $5.8 \%$. The extraction result with $\mathrm{n}$-hexane solvent resulted in $0.7 \mathrm{~g}$, so the yield percentage was $0.7 \%$. The difference in yield percentage is due to differences in the solubility of the extracted compound in each solvent used to affect the yield and characteristics of the extracted chemical compound. The n-hexane solvent is intended to dissolve semi-polar to nonpolar compounds, while methanol is used to dissolve more polar compounds. Compounds could be nonpolar compounds if they have bonds between atoms with an attractive ability to gain electrons together, resulting in a distant state where the electrons are shared equally. Meanwhile, if a compound has one atom capable of attracting electrons stronger than other atoms and the electrons from the bond will not be used together equally. This is called a polar compound (Tunega et al., 2020). These results are similar to those of (Azka and Abdullah 2012). They showed that the 
secondary metabolites of water clover ferns Marsilea crenata, most of them also dissolved in polar solvents with the yield of methanol extract of $11.98 \%$, ethyl acetate extract of $1.37 \%$, and chloroform of extract of $0.31 \%$. Thus, methanol is a polar solvent, while ethyl acetate and chloroform are semi-polar and nonpolar solvents.

\section{Thin-layer chromatography profile analysis}

Research shows that $L$. obtusa extract contains terpenoid and steroid compounds. This is indicated by a positive reaction to the Liebermann-Burchard reagent (Table 2). The Liebermann-Burchard response was first described by Liebermann and then extensively developed by Burchard (Xiong et al. 2007). The LiebermannBurchard reaction has been studied to determine the sterol content. Libermann Burchard reagent produces a varied color response depending on the double bond system, other functional groups, and the presence of nonpolar bonds (Xiong et al. 2002). Thus, Liebermann-Burchard is a spotting reagent for detecting steroids and terpenoids. This analysis was based on the ability of terpenoid and steroid compounds to form a color with concentrated $\mathrm{H} 2 \mathrm{SO} 4$ in acetic anhydride acid (Parbuntari et al., 2018). Therefore, the Liebermann-Burchard reagent will show a red-violet stain indicating the presence of terpenoid compounds. In contrast, the presence of steroids is indicated by the appearance of a reddish-brown stain.

Two fractions give negative results in the detection of terpenoids with no visible red-violet spots, namely in the mobile phase methanol extract of chloroform: n-hexane (9: $1 \mathrm{v} / \mathrm{v})$ and $\mathrm{n}$-hexane extract in the mobile phase of methanol: ethyl acetate $(5: 1 \mathrm{v} / \mathrm{v})$ (Table 2$)$. In the detection of steroids, two fractions gave negative results with no visible reddish-brown spots, namely the mobile phase methanol extract n-hexane: ethyl acetate (4: $1 \mathrm{v} / \mathrm{v}) \mathrm{n}-$ hexane extract in the mobile phase of methanol: ethyl. acetate $(5: 1 \mathrm{v} / \mathrm{v})$.

Table 3 shows that the $\mathrm{Rf}$ values for detecting terpenoid compounds in the mobile phase of chloroform: n-hexane (9: $1 \mathrm{v} / \mathrm{v}) \mathrm{n}$-hexane extract are found at Rf 0.820 .93 . The methanol extract in the mobile phase of n-hexane: ethyl acetate $(4: 1 \mathrm{v} / \mathrm{v})$ was found at $\mathrm{Rf} 0.90$ and for $\mathrm{n}$-hexane extract $0.42 ; 0.76$; and 0.85 . Methanol extract in the mobile phase of methanol: ethyl acetate $(5: 1 \mathrm{v} / \mathrm{v})$ was found at $\mathrm{Rf}$ 0.73 and 0.88 . Meanwhile, the $\mathrm{Rf}$ value for the detection of steroid compounds in the mobile phase of chloroform: nhexane $(9: 1 \mathrm{v} / \mathrm{v})$ methanol extract was found at Rf 0.93 and for $n$-hexane extract $0.49 ; 0.64 ; 0.73 ; 0.86$; and 0.90 . The n-hexane extract in the mobile phase of $n$-hexane: ethyl acetate $(4: 1 \mathrm{v} / \mathrm{v})$ was found at $\operatorname{Rf} 0.34 ; 0.48 ; 0.58$; and 0.96 . Methanol extract in the mobile phase of methanol: ethyl acetate $(5: 1 \mathrm{v} / \mathrm{v})$ was found at $\mathrm{Rf} 0.78$. These results indicate that the $n$-hexane extract gave clearer results than the methanol extract, especially in the mobile phase of nhexane: ethyl acetate $(4: 1 \mathrm{v} / \mathrm{v})$.

Tabel 1. Maceration result of Lindsaea obtusa extract

\begin{tabular}{lccc}
\hline Solvent & Powder mass (g) & Extract mass (g) & Yield (\%) \\
\hline Methanol & 100 & 5.8 & 5.8 \\
N-hexane & 100 & 0.7 & 0.7 \\
\hline
\end{tabular}

Table 2. Thin Layer Chromatography Profile (TLC) of Lindsaea obtusa extract with Liebermann-Burchard reagent

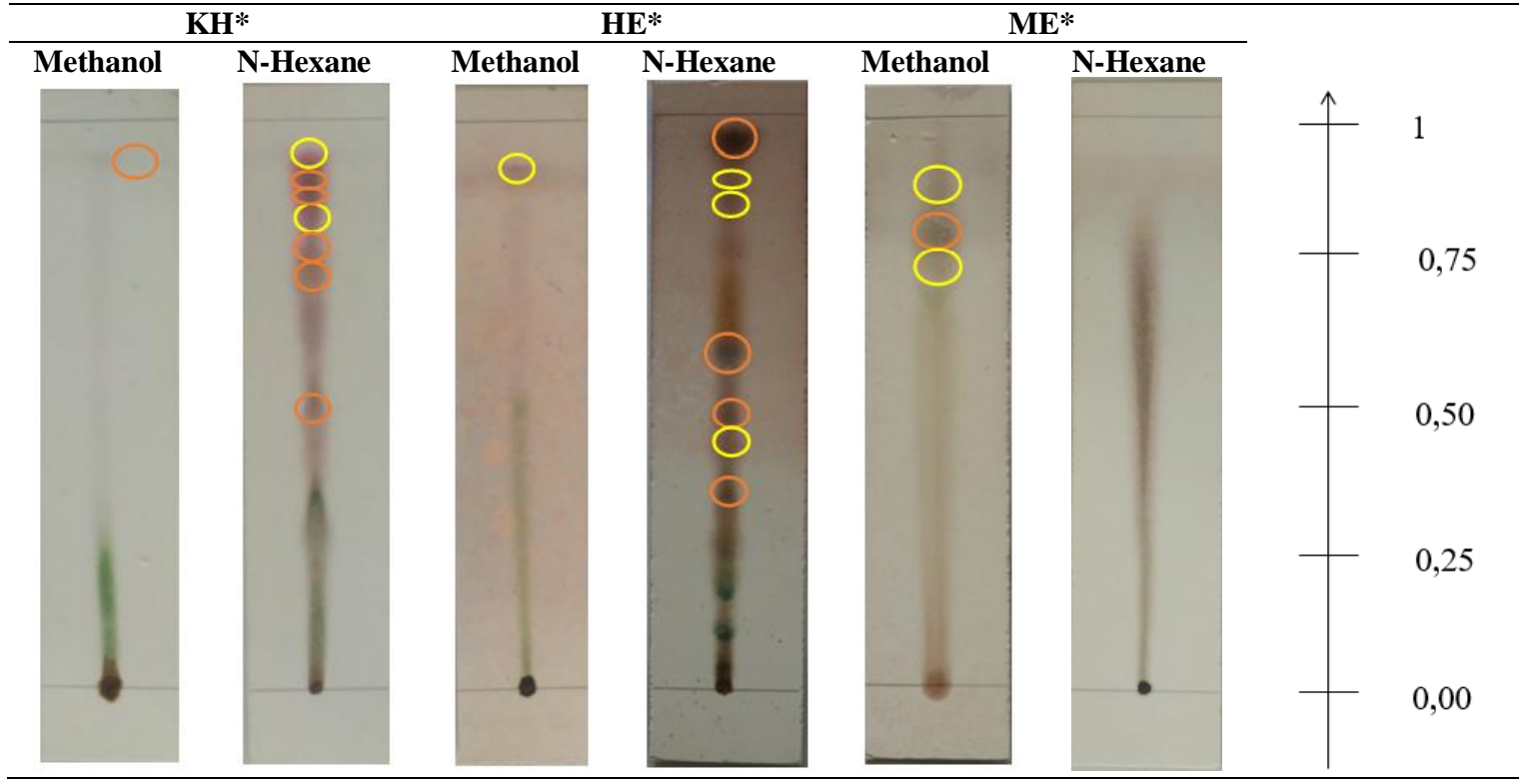

Note: $* \mathrm{KH}=$ chloroform: $\mathrm{n}$-hexane $(9: 1 \mathrm{v} / \mathrm{v}) ; \mathrm{HE}=\mathrm{n}$-hexane: ethyl acetate $(4: 1 \mathrm{v} / \mathrm{v}) ; \mathrm{ME}=$ methanol: ethyl acetate $(5: 1 \mathrm{v} / \mathrm{v})$. The yellow sign indicates the presence of a terpenoid compound, and the orange sign indicates the presence of a steroid compound 
Table 3. Retardation factor (Rf) value of Lindsaea obtusa extract with Liebermann-Burchard reagent

\begin{tabular}{|c|c|c|c|c|c|c|}
\hline \multirow{2}{*}{ Senyawa } & \multicolumn{2}{|c|}{ KH } & \multicolumn{2}{|c|}{ HE } & \multicolumn{2}{|c|}{ ME } \\
\hline & Methanol & N-Hexane & Methanol & N- Hexane & Methanol & N-Hexane \\
\hline \multirow[t]{3}{*}{ Terpenoid } & - & 0.82 & 0.9 & 0.42 & 0.73 & - \\
\hline & & 0.92 & & 0.76 & 0.88 & \\
\hline & & & & 0.85 & & \\
\hline \multirow[t]{5}{*}{ Steroid } & 0.93 & 0.49 & - & 0.34 & 0.78 & - \\
\hline & & 0.64 & & 0.48 & & \\
\hline & & 0.73 & & 0.58 & & \\
\hline & & 0.86 & & 0.96 & & \\
\hline & & 0.9 & & & & \\
\hline
\end{tabular}

Note: $* \mathrm{KH}=$ chloroform: $\mathrm{n}$-hexane $(9: 1 \mathrm{v} / \mathrm{v}) ; \mathrm{HE}=\mathrm{n}$-hexane: ethyl acetate $(4: 1 \mathrm{v} / \mathrm{v}) ; \mathrm{ME}=$ methanol: ethyl acetate $(5: 1 \mathrm{v} / \mathrm{v})$.

This is also found in medicinal Herb Hypochaeris radiata using the High-Performance Thin Layer Chromatography (HPTLC) technique (Senguttuvan and Subramaniam 2016). The thin layer chromatography profile showed that red-violet spots were more visible in the n-hexane extract than in the methanol extract. This is consistent with the nonpolar secondary metabolites of terpenoids and steroids. Most of the terpenoid compounds also contain an $-\mathrm{OH}$ group, so the presence of a hydroxyl group substituent attached to the hydrocarbon chain can be attracted by semi-polar and even polar solvents (Stachowiak et al., 2020). So, it can be concluded that $L$. obtusa positively contains secondary metabolites in the form of terpenoids and steroids. Other ferns, such as Azolla microphylla, contain terpenoid and steroid compounds (Rashad 2021).

In conclusion, Lindsaea obtusa J. Sm. ex Hook extract contains terpenoid and steroid compounds. Quantitatively, the secondary metabolites of $L$. obtusa extract that were soluble in methanol solvent were more than the soluble compounds in n-hexane. However, qualitatively, steroid compounds that dissolve in n-hexane solvents have a more varied $\mathrm{Rf}$ value than terpenoids, especially in the mobile phase of chloroform: n-hexane (9: $1 \mathrm{v} / \mathrm{v})$ and n-hexane: ethyl acetate $(4: 1 \mathrm{v} / \mathrm{v})$.

\section{REFERENCES}

Azka A, Abdullah A. 2012. Antioxidant activity and bioactive components of water clover (Marsilea crenata). Asian Journal of Innovation and Entrepreneurship (AJIE) 1 (3): 152-158. [Indonesian]

Bansal R, Singh R. 2018. Exploring the potential of natural and synthetic neuroprotective steroids against neurodegenerative disorders: A literature review. Med Res Rev 38 (4) : 1126-1158. DOI: $10.1002 / \mathrm{med} .21458$

Dong SY, Zuo ZY, Chao YS, Damas K, Sule B. 2016. New species of the fern genus Lindsaea (Lindsaeaceae) from New Guinea with notes on the phylogeny of $L$. Sect. Synaphlebium. PLoS ONE 11 (10): e0163686. DOI:10.1371/journal.pone.0163686

Gummadi SB, Belvotagi VAR, Kommidi DR, Bobbala RK, Achanta VNAR, Sterner O. 2021. Steroidal glycosides from Caralluma pauciflora. Phytochem Lett 41: 43-48. DOI: 10.1016/j.phytol.2020.10.016

Kim T, Song B, Cho KS, Lee IS. 2020. Therapeutic potential of volatile terpenes and terpenoids from forests for inflammatory diseases. Int $\mathrm{J}$ Mol Sci 21 (6): 2187. DOI: 10.3390/ijms21062187

Kruk A, Piwowarski JP, Pawłowska KA, Popowski D, Granica S. 2021. High molecular pyrogens present in plant extracts interfere with examinations of their immunomodulatory properties in vitro. Sci Rep 11 (1): 799. DOI: 10.1038/s41598-020-79579-2
Machfira Y, Nery S, Fitmawati. 2016. Pteridaceae diversity based on morphological and phytochemical characters in PT. Chevron Pacific Indonesia (PT. CPI) Rumbai. J Riau Biologia 1 (2): 165-172. [Indonesian]

Parbuntari H, Prestica Y, Gunawan R, Nurman MN, Adella F. 2018. Preliminary phytochemical screening (qualitative analysis) of cacao leaves (Theobroma Cacao L.). Eksakta 19 (2): 1-8. DOI: 10.24036/eksakta/vol19-iss2/142

Rashad S. 2021. An overview on the aquatic fern Azolla spp. as a sustainable source of nutrients and bioactive compounds with resourceful applications. Egyptian J Aquat Biol Fish 25 (1): 775-782. DOI: 10.21608/ejabf.2021.150205

Rashidinejad A, Marze S, Singh H. 2021. Lipid digestion and bioaccessibility of lipid-soluble compounds. In: Grundy MML, Wilde PJ (eds). Bioaccessibility and Digestibility of Lipids from Food. Springer, Cham. DOI: 10.1007/978-3-030-56909-9_10

Rubiyanto D. 2013. Teknik Dasar Kromatografi. Deepublish, Yogyakarta. [Indonesian]

Sati P, Dhyani P, Bhatt ID, Pandey A. 2019. Ginkgo biloba flavonoid glycosides in antimicrobial perspective with reference to extraction method. J Trad Complem Med 9 (1): 15-23. DOI: 10.1016/j.jtcme.2017.10.003

Senguttuvan J, Subramaniam P. 2016. HPTLC fingerprints of various secondary metabolites in the traditional medicinal herb Hypochaeris radicata L. J Bot 2016: 5429625. DOI: 10.1155/2016/5429625

Seremet L, Nistor OV, Andronoiu DG, Mocanu GD, Barbu VV, Maidan A, Rudi L, Botez E. 2020. Development of several hybrid drying methods used to obtain red beetroot powder. Food Chem 310: 125637. DOI: 10.1016/j.foodchem.2019.125637

Stachowiak W, Rzemieniecki T, Klejdysz T, Pernak J, Niemczak M. 2020. "Sweet" ionic liquids comprising the acesulfame anion synthesis, physicochemical properties and antifeedant activity towards stored product insects. New J Chem 44 (17): 7017-7028. DOI: $10.1039 / \mathrm{C} 9 \mathrm{NJ} 06005 \mathrm{G}$

Tunega D, Gerzabek MH, Haberhauer G, Lischka H, Solc R, Aquino AJA. 2020. Adsorption process of polar and nonpolar compounds in a nanopore model of humic substances. Europe J Soil Sci 71 (5): 845855. DOI: $10.1039 / \mathrm{C} 9 \mathrm{NJ} 06005 \mathrm{G}$

Wahyuni DT, Widjanarko SB. 2015. Effect of solvent type and extraction time on pumpkin carotenoid extract by ultrasonic wave method. J Food Agroind 3 (2): 390-401. [Indonesian]

Xiong Q, Ruan B, Whitby FG, Tuohy RP, Belanger TL, Kelley RI, Wilson WK, Schroepfer GJ Jr. 2002. A colorimetric assay for 7dehydrocholesterol with potential application to screening for SmithLemli-Opitz syndrome. Chem Phys Lipids 115 (1-2):1 -15. DOI: 10.1016/s0009-3084(01)00205-5

Xiong Q, Wilson WK, Pang J. 2007. The Liebermann-Burchard Reaction: Sulfonation, desaturation, and rearrangment of cholesterol in acid. Lipids 42: 87-96. DOI: 10.1007/s11745-006-3013-5

Yin D, Guan Y, Gu H, Jia Y, Zhang Q. 2017. Polymerized high internal phase emulsion monolithic material: A novel stationary phase of thin layer chromatography. RSC Adv 7 (12): 7303-7309. DOI: 10.1039/C6RA27609A

Yokota T, Ohnishi T, Shibata K, Asahina M, Nomura T, Fujita T, Ishizaki K, Kohchi T. 2017. Occurrence of brassinosteroids in non-flowering land plants, liverwort, moss, lycophyte and fern. Phytochem 136: 4655. DOI: 10.1016/j.phytochem.2016.12.020 